\title{
Change in local dynamics of bacteriorhodopsin with retinal isomerization under pressure as studied by fast magic angle spinning NMR
}

\begin{abstract}
Izuru Kawamura ${ }^{1}$, Satoru Yamaguchi ${ }^{2,3}$, Hirohide Nishikawa ${ }^{1}$, Kana Tajima ${ }^{1}$, Miyako Horigome ${ }^{1}$, Satoru Tuzi ${ }^{2}$, Hazime Saitô ${ }^{2}$ and Akira Naito ${ }^{1}$

Bacteriorhodopsin (bR) has a retinal with all-trans and 13-cis, 15-syn configurations whose isomeric ratio is close to 1 in the dark-adapted $\mathrm{bR}$, and the population of the 13-cis, 15-syn configuration can be increased under pressure. In our previous study, we applied pressure to $\mathrm{bR}$ using centrifugal force introduced by sample spinning and demonstrated that the ${ }^{15} \mathrm{~N}$ nuclear magnetic resonance (NMR) signal intensity of the Schiff base in 13-cis, 15-syn retinal increased. In this study, we demonstrate a pressure-induced change in the local dynamics of the protein side in the vicinity of retinal. In the ${ }^{13} \mathrm{C}$ dipolar decoupling and magic angle-spinning NMR spectra of $\left[3-{ }^{13} \mathrm{C}\right] \mathrm{Ala}$-labeled bR under fast spinning at 10 and $12 \mathrm{kHz}$, corresponding to 44 and 63 bar, respectively, the ${ }^{13} \mathrm{C}$ NMR signal at 16.6 p.p.m. appeared prominently as a sharp peak. This peak is assigned to Ala81 and Ala84 residues located in the vicinity of the retinal. It was observed that the change in the local dynamics in the vicinity of the retinal was caused by the applied pressure. These experiments demonstrate that fast magic angle spinning in NMR provides a pressure source for investigating the structure and change in the dynamics of biomacromolecules.
\end{abstract}

Polymer Journal (2012) 44, 863-867; doi:10.1038/pj.2012.116; published online 13 June 2012

Keywords: bacteriorhodopsin; dynamics; fast magic angle spinning; retinal; solid-state NMR

\section{INTRODUCTION}

Solid-state nuclear magnetic resonance (NMR) spectroscopy can provide detailed information regarding the conformation, orientation and dynamics of insoluble biological macromolecules such as membrane proteins and fibrils without an upper limit of molecular weight. ${ }^{1-5}$ Consequently, solid-state NMR is directly applied to understand the native state of biological macromolecules under ambient conditions. Furthermore, the solid-state NMR method is able to be combined with thermodynamic perturbations such as temperature and pressure to investigate how the structure and dynamics of biological macromolecules are related to their functional states. Therefore, we performed solid-state NMR studies by applying pressure as perturbations to a sample. ${ }^{6,7}$ Recently, we developed in-situ photo-irradiated solid-state NMR to induce the photo excitation and efficiently detected the photo-activated intermediate of a photoreceptor protein. ${ }^{8}$

Bacteriorhodopsin (bR) in a purple membrane (PM) of $H$. salinarum reveals a light-driven proton pump during the photoisomerization of retinal. ${ }^{9}$ The all-trans and 13-cis, 15-syn retinal configurations in the dark-adapted bR coexist in an isomeric ratio close to $1 .^{10,11}$ Interestingly, the all-trans state only shows light-driven proton pump activity. ${ }^{12-14}$ The population of the 13-cis, 15-syn retinal in an inactive state increases under pressure with a negative change in molar volume, as reported by various groups. ${ }^{15-17}$ Pressure effects on $\mathrm{bR}$ in the dark have suggested that the isomer equilibrium constant of the all-trans to 13-cis, 15-syn states decreases via two processes that induce different negative changes in molar volume upon the application of pressure. ${ }^{17}$ The first process, which occurs at $10 \mathrm{MPa}$, may be caused by the change in the conformations of functionally important residues, such as Tyr185 and Asp212 in the vicinity of retinal. We have also observed the pressure-induced isomerization of retinal from the ${ }^{15} \mathrm{~N}$ NMR signals of the protonated Schiff base in retinal using fast magic angle-spinning (MAS) experiments. ${ }^{6}$ MAS can eliminate the chemical shift anisotropy when the sample rotation axis is inclined $54.7^{\circ}$ to the external magnetic field and the spinning frequency of the rotor is larger than the chemical shift anisotropy. ${ }^{18,19}$ We observed that sample spinning generates pressure for the fully hydrated sample as a function of the square of the rotor-spinning frequency and radius because the centrifugal force is divided by the wall area of the rotor. Pressure-induced protein structure, cell-volume changes, pharmaceutical samples and rubbers have all been characterized using fast MAS techniques. ${ }^{20-25}$

In this study, we demonstrated that the significant changes in the dynamics of protein induced by fast sample spinning occur in

${ }^{1}$ Graduate School of Engineering, Yokohama National University, Yokohama, Japan; ${ }^{2}$ Graduate School of Life Science, University of Hyogo, Harima Science Garden City, Hyogo, Japan and ${ }^{3}$ Department of Life Science, Okayama University of Science, Okayama, Japan 
the vicinity of retinal. In our previous studies, we assigned the major signals observed for bR by analyzing the associated local conformation and dynamics using a site-directed solid-state NMR approach. ${ }^{26,27}$ In particular, we observed that the ${ }^{13} \mathrm{C}$ NMR peaks were well-resolved for the fully hydrated $\left[3-{ }^{13} \mathrm{C}\right]$ Ala and $\left[1-{ }^{13} \mathrm{C}\right]$ Val-labeled bR, depending on their locations and characteristic local dynamics and conformations. ${ }^{28,29}$ In addition, we simultaneously observed two NMR signals of Tyr185 at 177.7 and 173.4 p.p.m. in the vicinity of retinal corresponding to the all-trans and 13-cis retinal configurations in the dark-adapted $\mathrm{bR}$ as disclosed by REDOR-filtered ${ }^{13} \mathrm{C}$ NMR spectra. ${ }^{7}$ The results showed that the signal intensity at 173.4 p.p.m. for the 13-cis, 15-syn retinal state increased considerably with the long accumulation time under the MAS condition, which is related to the large population of the 13-cis, 15-syn configuration in pressure-adapted bR. Therefore, in this study, we used $\left[3-{ }^{13} \mathrm{C}\right]$ Ala- and $\left[1-{ }^{13} \mathrm{C}\right]$ Val-labeled bR in PM and investigated the protein structure and changes in the dynamics of pressure-adapted $b R$.

\section{MATERIALS AND METHODS}

Halobacterium salinarum S9 was grown in synthetic medium featuring $\left[3-{ }^{13} \mathrm{C}\right]-\mathrm{L}-\mathrm{Ala}$ and $\left[1-{ }^{13} \mathrm{C}\right]-\mathrm{L}-\mathrm{Val}$ to yield stable isotope-labeled bR in PM. PM was isolated by the standard method described elsewhere ${ }^{30}$ and suspended in 5 mM HEPES buffer containing $0.02 \% \mathrm{NaN}_{3}$ and $10 \mathrm{~mm} \mathrm{NaCl}$ at $\mathrm{pH}$. The hydrated sample was collected by centrifugation and packed in a $4.0-\mathrm{mm}$ o.d. zirconia rotor for the fast magic angle-spinning experiments. The sample rotor was tightly shielded by a Teflon cap and glued to the rotor with Araldite Rapid to prevent the dehydration of the pelleted sample.

${ }^{13} \mathrm{C}$ high-resolution solid-state NMR spectra were recorded on a Chemagnetics CMX-400 infinity FT-NMR spectrometer, operating at $100.16 \mathrm{MHz}$ for carbon nuclei, equipped with a $4.0-\mathrm{mm}$ double resonance MAS probe. Cross polarization magic angle spinning (CP-MAS) with a variable amplitude contact pulse of observed nucleus and single-pulse excitation with dipolar decoupling and magic angle-spinning (DD-MAS) experiments were performed. The spinning frequencies were set in the range from 4 to $12 \mathrm{kHz}$ in $2 \mathrm{kHz}$ steps, and the $90^{\circ}$ pulse length for the observed carbon nucleus was $5.1 \mu$ s. Variable amplitude CP-MAS with TPPM decoupling was used with a $10.0 \mu$ s phasemodulated pulse train for proton decoupling. ${ }^{31}$ The ${ }^{13} \mathrm{C}$ contact and repetition times were set to $1 \mathrm{~ms}$ and $4 \mathrm{~s}$, respectively. ${ }^{13} \mathrm{C}$ chemical shifts were externally referenced to 176.03 p.p.m. for the carbonyl carbon of glycine from TMS.

Ambient conditions were used for the MAS experiment at $4 \mathrm{kHz}$, and the probe temperature was set to $20^{\circ} \mathrm{C}$. After performing the measurements under the pressure induced by the fast spinning at $12 \mathrm{kHz}$, the NMR spectrum at $4 \mathrm{kHz}$ was quickly collected again. The sample temperature was increased by friction under the fast sample-spinning conditions. Temperature was measured within the rotor by monitoring the ${ }^{207} \mathrm{~Pb}$ chemical shifts of lead nitrate. ${ }^{32}$

\section{RESULTS AND DISCUSSION}

To verify the conformation and changes in the dynamics of the protein side under the pressurized condition, we compared the NMR spectrum of the dark-adapted $\mathrm{bR}$ at the initial MAS-spinning frequency of $4 \mathrm{kHz}$ with that of the pressure-adapted bR at the same spinning frequency immediately after the fast-spinning experiments. In a previous study, we observed the same ${ }^{15} \mathrm{~N}$ NMR signal intensities of the Schiff base in the dark-adapted bR owing to the coexistence of all-trans and 13-cis, 15-syn retinal configurations at $4 \mathrm{kHz} .{ }^{6}$ When the MAS frequency was increased to $12 \mathrm{kHz}$, the ${ }^{15} \mathrm{~N}$ NMR signals showed large broadening. Immediately after the measurement at an MAS-spinning frequency of $12 \mathrm{kHz}$, we recorded the NMR spectrum at $4 \mathrm{kHz}$ again. The ${ }^{15} \mathrm{~N}$ NMR signal intensity of the 13-cis, 15-syn retinal observed at a MAS-spinning frequency of $4 \mathrm{kHz}$ clearly increased compared with the initial signal intensity. Thus, the retinal configurations in bR indicate that it takes $60 \mathrm{~h}$ for the pressure to reach equilibrium in the fast MAS experiments, and we can distinguish pressure-adapted bR from dark-adapted bR. ${ }^{7}$ The pressure applied to the sample packed in the $4 \mathrm{~mm}$ rotor at an MAS-spinning frequency of $12 \mathrm{kHz}$ was calculated to be 63 bar along the inner rotor wall according to the following equation:

$$
P=\left(4 \pi^{2} / 3\right) r^{2} v^{2} \rho
$$

where $r, v$ and $\rho$ are rotor radius, MAS-spinning frequency and sample density, respectively.

Figure 1 shows the ${ }^{13} \mathrm{C}$ DD-MAS NMR spectra of $\left[3-{ }^{13} \mathrm{C}\right] \mathrm{Ala}-$ labeled bR at spinning frequencies of $4,6,8,10$ and $12 \mathrm{kHz}$ in the dark and the spectrum obtained at $4 \mathrm{kHz}$ after the fast-spinning frequencies were applied. Interestingly, in the spectra obtained under the fast-spinning frequencies of 10 and $12 \mathrm{kHz}$, the ${ }^{13} \mathrm{C}$ NMR signal at 16.6 p.p.m. appeared prominently as a sharp peak (Figure 1d and e)

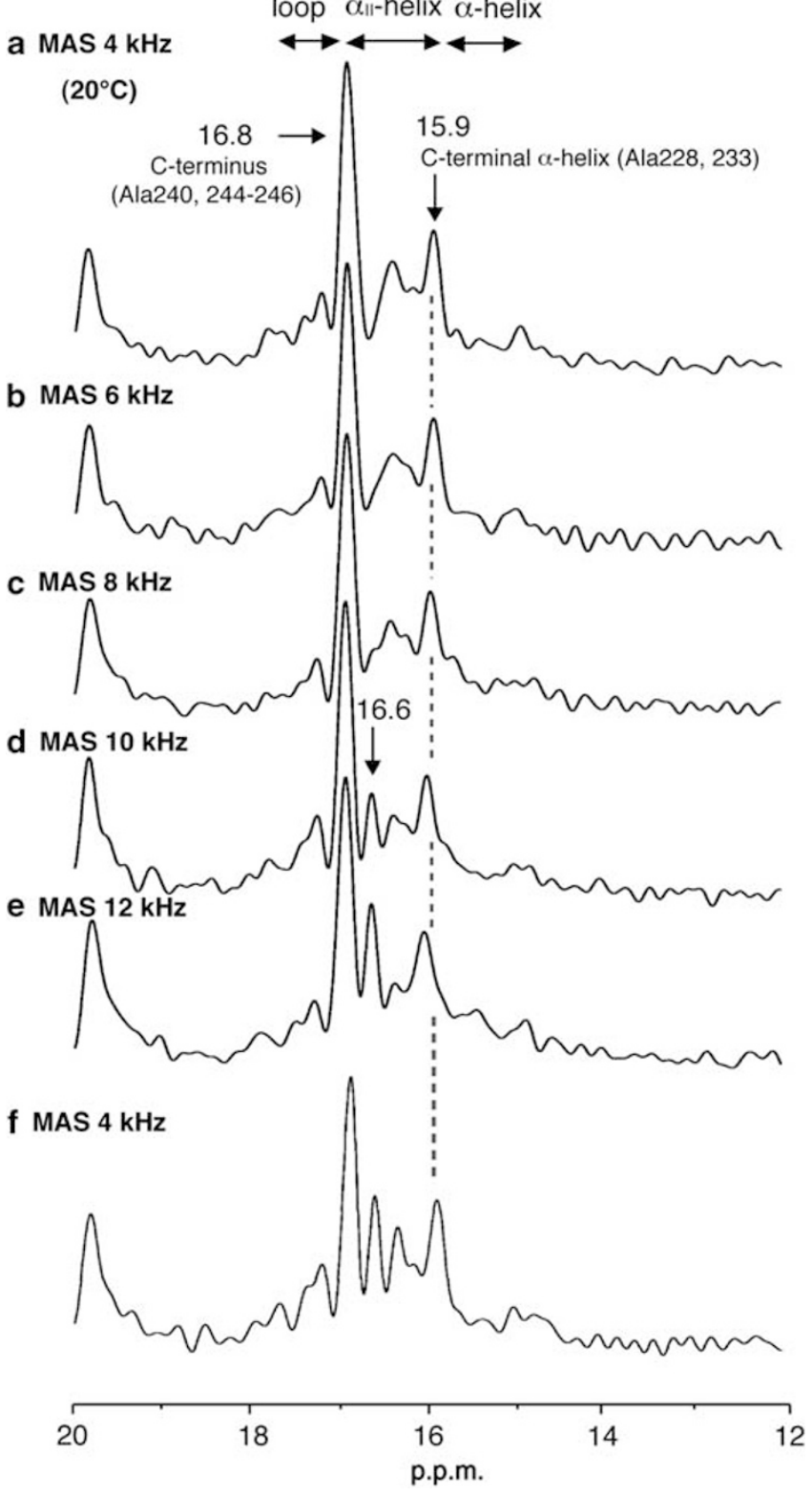

Figure $1{ }^{13} \mathrm{C}$ DD-MAS NMR spectra of $\left[{ }^{[3-13} \mathrm{C}\right]$ Ala-bR at various MAS frequencies up to $12 \mathrm{kHz}$ in the range from 4 to $12 \mathrm{kHz}$ in $2 \mathrm{kHz}$ steps (a-e). Immediately after sample spinning at $12 \mathrm{kHz}$, the ${ }^{13} \mathrm{C}$ DD-MAS NMR spectrum of pressure-adapted $\mathrm{bR}$ was recorded at $4 \mathrm{kHz}$ (f). 
This signal indicates a component of the pressure-adapted bR, because the signal was sufficiently retained at $4 \mathrm{kHz}$ after releasing the pressure at the spinning frequency of $12 \mathrm{kHz}$ (Figure 1f). This newly apparent signal corresponds to the change in the all-trans to 13-cis, 15-syn retinal configurations because of fast MAS. Using sitedirected $\mathrm{A} 81 \mathrm{G}$ and $\mathrm{A} 84 \mathrm{G}$ protein mutants, we assigned this peak at 16.6p.p.m. to Ala81 and Ala84 near the Schiff base and the extracellular side in the ${ }^{13} \mathrm{C}$ CP-MAS NMR spectra. ${ }^{33}$ Therefore, this DD-MAS signal at 16.6 p.p.m. was assigned to the Ala81 and Ala84 residues in the vicinity of retinal and indicates fast molecular motions induced by an applied pressure of 44 bar. Therefore, it is suggested that this component at 16.6 p.p.m. is caused by high populations of 13-cis, 15-syn retinal in pressure-adapted bR. Fast MAS also generates increased sample temperature owing to heating by friction between the rotor and air. Thus, we measured the sample temperature within the rotor under the corresponding fast MAS conditions by monitoring the ${ }^{207} \mathrm{~Pb}$ chemical shifts of lead nitrate (Figure S1 in Supporting Information). We observed that the sample temperature increased from 20 to $40^{\circ} \mathrm{C}$ at a MAS frequency of $12 \mathrm{kHz}$. Therefore, the temperature increased to $40^{\circ} \mathrm{C}$ because of the sample spinning at $12 \mathrm{kHz}$. The NMR signal of the C-terminal $\alpha$-helix of Ala228 and 233 at 15.9 p.p.m., which was used as a temperature indicator, slightly shifts to lower values with increasing MAS frequency in the same manner as the temperature variation. ${ }^{34}$ After fast sample spinning, the signal of the C-terminal $\alpha$-helix returned to its initial position at 15.9 p.p.m. at $4 \mathrm{kHz}$ (Figure 1f). However, the pressure-induced peak at 16.6 p.p.m. (Figure 1d-f) did not appear when the sample temperature was set to $40{ }^{\circ} \mathrm{C}$. However, the retinal isomeric ratio in the dark-adapted bR did not change upon the variation in temperature, as was revealed in the ${ }^{15} \mathrm{~N}$ CP-MAS NMR spectra of $\left[\zeta-{ }^{15} \mathrm{~N}\right]$ Lys-labeled bR (Figure S2 in Supporting Information). Thus, the retinal isomeric ratio is insensitive to the variation in temperature, as has been reported in other studies. ${ }^{15,16}$ Therefore, the increase in pressure is owing to fast-MAS-induced changes in dynamics at around Ala81 and Ala84, together with retinal isomerization from all-trans to 13-cis configurations.

Figure 2 shows the ${ }^{13} \mathrm{C}$ CP-MAS NMR spectra of $\left[3-{ }^{13} \mathrm{C}\right]$ Ala-labeled bR at $4,6,8,10$ and $12 \mathrm{kHz}$. At 10 and $12 \mathrm{kHz}$, the changes in the spectral pattern may be due to increased temperature, because similar NMR spectra have been observed at elevated temperature. ${ }^{34}$ After the fast-spinning experiments, the ${ }^{13} \mathrm{C}$ CP-MAS NMR spectrum of pressure-adapted bR at a MAS-spinning frequency of $4 \mathrm{kHz}$ remained mostly unchanged compared with that of dark-adapted bR at $4 \mathrm{kHz}$. The only change observed was the reduction in the peak intensity at 16.6-16.8 p.p.m. (Figure 2f). These peaks are also assigned to Ala81 and Ala84 located near the retinal (Figure S3 in Supporting Information). In fact, the peak position of this reduced peak consists of the newly appeared peak associated with the pressure effect in the DD-MAS NMR experiments (Figure 1). Thus, these results indicate that the dynamics of the Ala81 and Ala84 residues were enhanced when the bR in PM was pressurized by fast sample spinning. To detect the effects of pressure on global protein conformations in $\mathrm{bR}$ from the narrow resolved signals of $\left[1-{ }^{13} \mathrm{C}\right]$ Val-labeled $\mathrm{bR}$, the spectral patterns of pressure-adapted bR were also compared with those of dark-adapted bR. Figure 3 shows the ${ }^{13} \mathrm{C}$ CP-MAS NMR spectra of $\left[1-{ }^{13} \mathrm{C}\right]$ Val-labeled bR at 4, 6, 8, 10 and $12 \mathrm{kHz}$. These spectral patterns, between the dark-adapted and pressureadapted bR at $4 \mathrm{kHz}$, remained almost unchanged (Figure $3 \mathrm{a}$ and $\mathrm{f}$ ). Thus, it was determined that the pressure-induced structural changes mainly appeared in the vicinity of retinal in bR.

In this study, we demonstrated that this ${ }^{13} \mathrm{C}$ NMR peak of $\left[3-{ }^{13} \mathrm{C}\right]$ Ala-labeled bR in hydrated PM clearly appears at 16.6 p.p.m. and that the dynamics associated with this phenomenon were dramatically enhanced by the all-trans to 13-cis, 15-syn isomerization of retinal with the increase in pressure in fast MAS experiments. ${ }^{6}$ As a result, the equilibrium constant of the all-trans to 13-cis, 15-syn reaction in the dark-adapted state of bR decreased. Moreover, it was
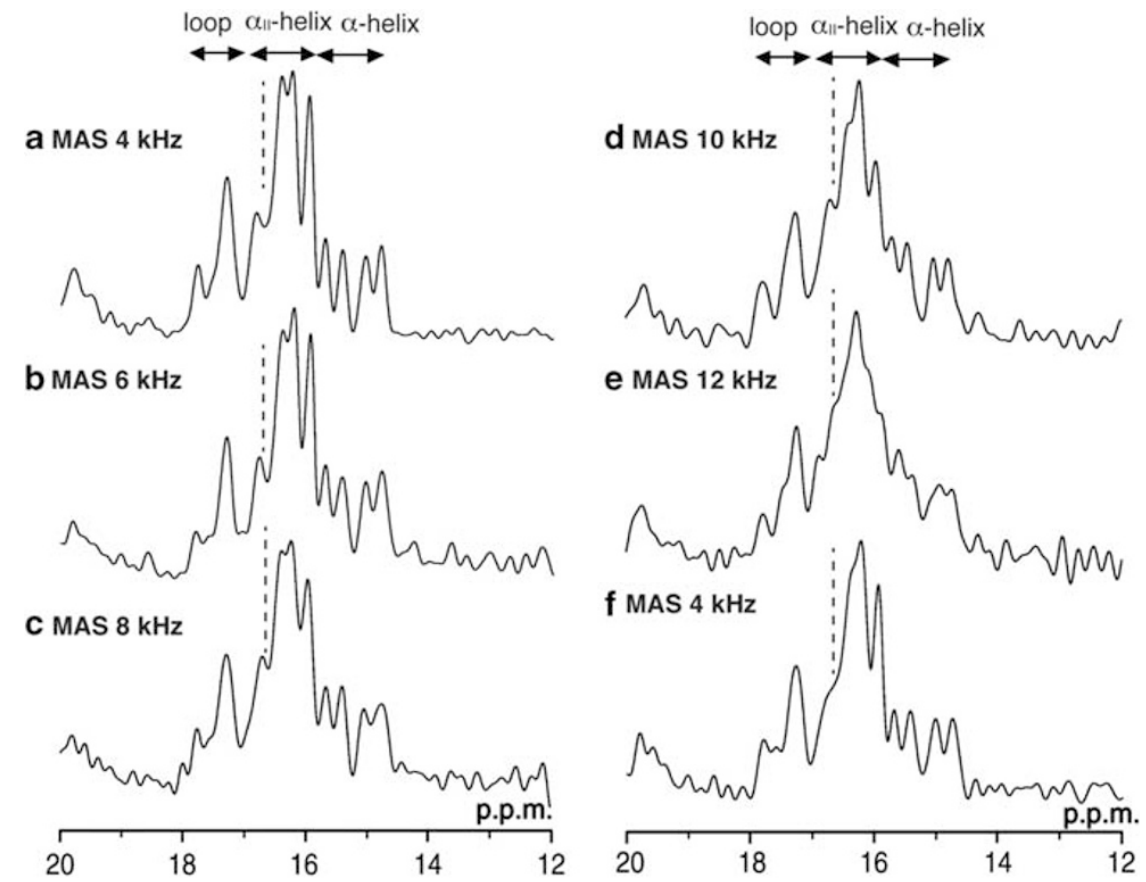

Figure $2{ }^{13} \mathrm{C}$ CP-MAS NMR spectra of $\left[3-{ }^{13} \mathrm{C}\right]$ Ala-bR at various MAS frequencies up to $12 \mathrm{kHz}$ in the range from 4 to $12 \mathrm{kHz}$ in $2 \mathrm{kHz}$ steps (a-e). In the ${ }^{13} \mathrm{C}$ CP-MAS NMR spectrum at $4 \mathrm{kHz}$ after sample spinning at $12 \mathrm{kHz}$ (f)—the ${ }^{13} \mathrm{C}$ NMR signal at $16.6 \mathrm{p} . \mathrm{p} . \mathrm{m}$. is shown as a dotted line (f)-the signal at 16.6-16.8 p.p.m. was reduced compared with that initially measured at $4 \mathrm{kHz}(\mathbf{a})$. 

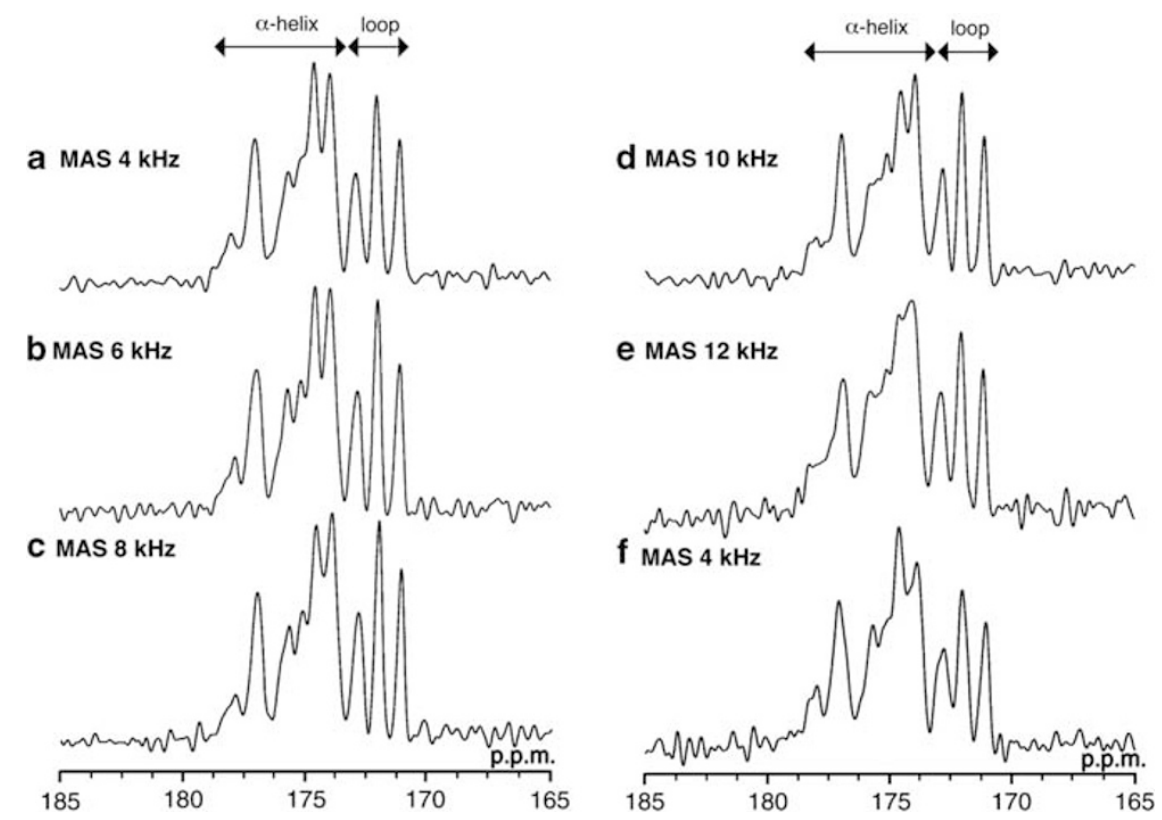

Figure $3{ }^{13} \mathrm{C}$ CP-MAS NMR spectra of $\left[1-{ }^{13} \mathrm{C}\right] \mathrm{Val}-\mathrm{bR}$ at MAS frequencies up to $12 \mathrm{kHz}$ in the range from 4 to $12 \mathrm{kHz}$ in $2 \mathrm{kHz}$ steps (a-e). After fast sample spinning at $12 \mathrm{kHz}$, the ${ }^{13} \mathrm{C}$ CP-MAS NMR spectrum was recorded at $4 \mathrm{kHz}(\mathbf{f})$.

confirmed by extraction techniques and absorption spectroscopy performed over a range of low to high pressure that the equilibrium constant of the all-trans to 13-cis, 15-syn isomerization decreased because of two processes that induce changes in molar volume in the dark. ${ }^{15-17}$ As the population of 13-cis, 15-syn increased with pressure, the dynamics of the Ala81 and Ala84 residues in the vicinity of retinal increased the signal intensity at 16.6 p.p.m. Therefore, we concluded that the change in the dynamics of the residues was coupled with the change in molar volume. The locations of internal water molecules in the vicinity of retinal were determined, and the formation of a hydrogen-bond network featuring retinal, Asp85 and some residues via water molecules was observed to be correlated with proton pump activity. ${ }^{9,35}$ As the hydrogen-bond distance between $\mathrm{H}$ and $\mathrm{O}(\mathrm{H} \bullet \bullet \bullet \mathrm{O})$ in the protein structure changed upon the application of pressure, inducing changes in molar volume, the volume change induced by pressure was attributed to hydration. ${ }^{36}$ It is concluded that the hydrated condition of bR was retained, as evidenced by the unchanging line widths (Figures 1-3), while the NMR signals of bR dehydrated by lyophilization were clearly broadened. ${ }^{37}$ It is suggested that the pressure caused by the fast MAS experiments induces the isomerization of retinal and modulates the hydrogen-bond network in $\mathrm{bR}$, and consequently, a change in the motion of the residues located in the vicinity of retinal is induced. The change in the local dynamics in the vicinity of retinal is closely related to the conformational change of Tyr185 in bR, as observed by solid-state MAS NMR. ${ }^{7}$

The effects of pressure on the change in the dynamics of bR appeared even in the low-pressure range of fast MAS. It is stressed that two retinal isomers, all-trans and 13-cis, 15-syn configurations, coexist in $\mathrm{bR}$ in a population ratio close to 1 , leading to the conclusion that both isomers have the same energy levels. This property induces structural and dynamical changes in bR, even for low-pressure changes. It should be noted that fast MAS NMR can be used to detect the equilibrium states of molecules for which high-pressure NMR spectroscopy ${ }^{36}$ is typically utilized, because an accurately recorded pressure is applied to samples along the internal wall of the rotor by fast spinning at controlled MAS frequencies and using a large rotor diameter. The pressure applied by fast MAS contributes to the clarification of functional protein states, such as those of membrane proteins.

\section{CONCLUSIONS}

We have shown that fast MAS experiments can be used to detect noticeable pressure effects on biomacromolecules at low pressures and investigate changes in conformation and dynamics. Pressure induced by fast MAS frequencies reduced the equilibrium constant of the alltrans to 13-cis, 15-syn isomerization of retinal and induced a dynamical change in site-directed residues in the vicinity of retinal in bR. It is concluded that this dynamical change was caused by the effects of pressure in the vicinity of retinal in bR.

\section{ACKNOWLEDGEMENTS}

This work was supported by a Grant-in-Aid for Scientific Research in Priority Area (21017102) and a Grant-in-Aid for Young Scientists (B) (22770101) from the Ministry of Culture, Sports, Science and Technology of Japan and a SUNBOR Grant from the SUNTORY Foundation for Life Sciences.

1 Judge, P. J. \& Watts, A. Recent contributions from solid-state NMR to the understanding of membrane protein structure and function. Curr. Opin. Chem. Biol. 15, 690-695 (2011).

2 Naito, A. Structure elucidation of membrane-associated peptides and proteins in oriented bilayers by solid-state NMR spectroscopy. Solid State Nucl. Magn. Reson. 36, 67-76 (2009).

3 Chimon, S. \& Ishii, Y. Capturing intermediate structures of Alzheimer's $\beta$-amyloid, $A \beta$ (1-40) by solid-state NMR spectroscopy. J. Am. Chem. Soc. 127, 13472-13473 (2005)

4 Asakura, T., Ohgo, K., Komatsu, K., Kanenari, M. \& Okuyama, K. Refinement of repeated $\beta$-turn structure for silk I conformation of Bombyx mori silk fibroin using ${ }^{13} \mathrm{C}$ solid-state NMR and X-ray diffraction methods. Macromolecules 38, 7397-7403 (2005). 
5 Shi, L., Kawamura, I., Jung, K. H., Brown, L. S. \& Ladizhansky, V. Conformation of a Seven-helical transmembrane photosensor in the lipid environment. Angew. Chem. Int Ed. 50, 1302-1305 (2011).

6 Kawamura, I., Degawa, Y., Yamaguchi, S., Nishimura, K., Tuzi, S., Saitô, H. \& Naito, A. Pressure-induced isomerization of retinal on bacteriorhodopsin as disclosed by fast magic angle spinning NMR. Photochem. Photobiol. 83, 346-350 (2007).

7 Kawamura, I., Kihara, N., Ohmine, M., Nishimura, K., Tuzi, S., Saitô, H. \& Naito, A. Solid-state NMR studies of two backbone conformations at Tyr185 as a function of retinal configurations in the dark, light, and pressure adapted bacteriorhodopsins. J. Am. Chem. Soc. 129, 1016-1017 (2007)

8 Tomonaga, Y., Hidaka, T., Kawamura, I., Nishio, T., Ohsawa, K., Okitsu, T., Wada, A., Sudo, Y., Kamo, N., Ramamoorthy, A. \& Naito, A. An active photoreceptor intermediate revealed by in situ photoirradiated solid-state NMR spectroscopy. Biophys. J. 101, L50-L52 (2011).

9 Luecke, H., Shobert, B., Richter, H. T., Cartailler, J. P. \& Lanyi, J. K. Structural changes in bacteriorhodopsin during ion transport at 2 angstrom resolution. Science 286, 255-261 (1999).

10 Maeda, A., Iwasa, T. \& Yoshizawa, T. Isomeric composition of retinal chromophore in dark-adapted bacteriorhodopsin. J. Biochem. 82, 1599-1604 (1977).

11 DeGroot, H. J. M., Harbison, G. S., Herzfeld, J. \& Griffin, R. G. Nuclear magnetic resonance study of the Schiff base in bacteriorhodopsin: counterion effects on the ${ }^{15} \mathrm{~N}$ shift anisotropy. Biochemistry 28, 3346-3353 (1989).

12 Kalisky, O., Goldschmidt, C. R. \& Ottolenghi, M. On the photocycle and light adaptation of dark-adapted bacteriorhodopsin. Biophys. J. 19, 185-189 (1977).

13 Hofrichter, J., Henry, E. R. \& Lozier, R. H. Photocycles of bacteriorhodopsin in lightand dark-adapted purple membrane studied by time-resolved absorption spectroscopy. Biophys. J. 56, 693-706 (1986).

14 Mizuide, N., Shibata, M., Friedman, N., Sheves, M., Belenky, M., Herzfeld, J. \& Kandori, H. Structural changes in bacteriorhodopsin following retinal photoisomerization from the 13-cis form. Biochemistry 45, 10674-10681 (2006).

15 Tsuda, M. \& Ebrey, T. G. Effect of high pressure on the absorption spectrum and isomeric composition of bacteriorhodopsin. Biophys. J. 30, 149-158 (1980).

16 Schulte, A. \& Bradley, L. High-pressure near-infrared raman spectroscopy of bacteriorhodopsin light to dark adaptation. Biophys. J. 69, 1554-1562 (1995).

$17 \mathrm{Bryl}, \mathrm{K}$. \& Yoshihara, K. Two processes lead to a stable all-trans and 13-cis isomer equilibrium in dark-adapted bacteriorhodopsin; effect of high-pressure on bacteriorhodopsin, bacteriorhodopsin mutant D96N and fluoro-bacteriorhodopsin analogues. Eur. Biophys. J 31, 539-548 (2002).

18 Andrew, E. R., Bradbury, A. \& Eades, R. G. Nuclear magnetic resonance spectra from a crystal rotated at high speed. Nature 182, 1659 (1958).

19 Lowe, I. J. Free induction decays of rotating solids. Phys. Rev. Lett. 2, 285-287 (1959).

20 Bertini, I., Luchinat, C., Parigi, G., Ravera, E., Reif, B. \& Turano, P. Solid-state NMR of proteins sedimented by ultracentrifugation. Proc. Natl Acad. Sci. 108, 10396-10399 (2011).

21 Kuchel, P. W., Bubb, W. A., Ramadan, S., Chapman, B. E., Philp, D. J., Coen, M., Gready, J. E., Harvey, P. J., McLean, A. J. \& Hock, J. ${ }^{31}$ P MAS-NMR of human erythrocytes: independence of cell volume from angular velocity. Magn. Reson. Med. 52, 663-668 (2004).
22 Apperley, D. C., Fletton, R. A., Harris, R. K., Lancaster, R. W., Tavener, S. \& Threlfall, T. L. Sulfathiazole polymorphism studied by magic-angle spinning NMR. J. Pharm. Sci. 88, 1275-1280 (1999).

23 Zell, M. T., Padden, B. E., Grant, D. J. W., Schroeder, S. A., Wachholder, K. L., Prakash, I. \& Munson, E. J. Investigation of polymorphism in aspartame and neotame using solid-state NMR spectroscopy. Tetrahedron 56, 6603-6616 (2000).

24 Xu, M. \& Harris, K. D. M. Altering the polymorphic product distribution in a solid-state dehydration process by rapid sample rotation in a solid-state NMR probe. J. Am. Chem. Soc. 127, 10832-10833.

25 Asano, A., Hori, S., Kitamura, M., Nakazawa, C. T. \& Kurosu, T. Influence of magic angle spinning on $T_{1}{ }^{\mathrm{H}}$ of SBR studied by solid state ${ }^{1} \mathrm{H}$ NMR. Polym. J. (e-pub ahead of print 7 March 2012; doi:10.138/pj.2012.10).

26 Saitô, $\mathrm{H}$. Conformation-dependent ${ }^{13} \mathrm{C}$ chemical shifts: A new means of conformational characterization as obtained by high-resolution solid-state ${ }^{13} \mathrm{C}$ NMR. Magn. Reson. Chem. 24, 835-852 (1986).

27 Saitô, H. \& Naito, A. NMR studies on fully hydrated membrane proteins, with emphasis on bacteriorhodopsin as a typical and prototype membrane protein. Biochem. Biophys. Acta-Biomembranes 1768, 3145-3161 (2007).

28 Tanio, M., Inoue, S., Yokota, K., Seki, T., Tuzi, S., Needleman, R., Lanyi, J. K., Naito, A. \& Saitô, H. Long-distance effects of site-directed mutations on backbone conformation in bacteriorhodopsin from solid state NMR of $\left[1-{ }^{13} \mathrm{C}\right]$ Val-labeled proteins. Biophys. J. 77, 431-442 (1999).

29 Tuzi, S., Tanio, M., Konishi, H., Inoue, S., Naito, A., Needleman, R., Lanyi, J. K. \& Saitô, H. Location of cation-binding site in the loop between helices $F$ and $G$ of bacteriorhodopsin as studied by ${ }^{13} \mathrm{C}$ NMR. Biophys. J. 76, 1523-1531 (1999).

30 Oesterhelt, D. \& Stoeckenius, W. Isolation of the cell membrane of Halobacterium halobium and its function into red and purple membrane. Methods Enzymol. 31, 667-678 (1974).

31 Benett, A. W., Rienstra, C. M., Auger, M., Lakshmi, K. V. \& Griffin, R. G. Heteronuclear decoupling in rotating solids. J. Chem. Phys. 103, 6951-6958 (1995).

32 Bielecki, A. \& Burum, D. P. Temperature Dependence of ${ }^{207} \mathrm{~Pb}$ MAS Spectra of Solid Lead Nitrate. An Accurate, Sensitive Thermometer for Variable-Temperature MAS. J. Magn. Reson. Ser. A. 116, 215-220 (1995).

33 Tuzi, S., Hasegawa, J., Kawaminami, R., Naito, A. \& Saitô, H. Regio-selective Detection of Dynamic Structure of Transmembrane $\alpha$-helices as Revealed from ${ }^{13} \mathrm{C}$ NMR spectra of $\left[3-{ }^{13} \mathrm{C}\right]$ Ala-labeled Bacteriorhodopsin in the Presence of $\mathrm{Mn}^{2+}$ Ion. Biophys. J 81, 425-434 (2001).

34 Yamaguchi, S., Yonebayashi, K., Konishi, H., Tuzi, S., Naito, A., Lanyi, J. K., Needleman, R. \& Saitô, H. Cytoplasmic surface structure of bacteriorhodopsin consisting of interhelical loops and C-terminal $\alpha$ helix, modified by a variety of environmental factors as studied by ${ }^{13} \mathrm{C}$ NMR. Eur. J. Biochem. 268, 2218-2228 (2001).

35 Shibata, M., Tanimoto, T. \& Kandori, H. Water Molecules in Schiff Base Region of Bacteriorhodopsin. J. Am. Chem. Soc. 125, 13312-13313 (2003).

36 Akasaka, K. Highly Fluctuating structures revealed by variable-pressure nuclear magnetic resonance. Biochemistry 42, 10875-10885 (2003).

37 Tuzi, S., Naito, A. \& Saitô, H. ${ }^{13} \mathrm{C}$ NMR Study on Conformation and Dynamics of the Transmembrane $\alpha$-Helices, Loops, and C-Terminus of $\left[3^{-13} \mathrm{C}\right]$ Ala-Labeled Bacteriorhodopsin. Biochemistry 33, 15046-15052 (1994).

Supplementary Information accompanies the paper on Polymer Journal website (http://www.nature.com/pj) 